\title{
Characterization of Propionyl Phosphate Hydrolysis Kinetics by Data-Rich Experiments and In-Line Process Analytical Technology
}

Cuixian Yang*1, Hanzhou Feng ${ }^{2}$, and Kevin Stone ${ }^{1}$

1. Small Molecular Process Research \& Development (SMPRD), MRL, Merck \& Co., Inc., Rahway, New Jersey 07065, USA

2. Process Analytical Technology, MMD, Merck \& Co., Inc., Rahway, New Jersey 07065, USA

\section{Experimental Procedure for Quantitative P-NMR}

Seven off-line samples were taken during the reaction and subjected to quantitative P-31 NMR analysis (Bruker NMR $500 \mathrm{MHz}$ ) to determine the concentrations of the starting material (propionyl phosphate monoammonium, named PrP mono in this study) and the product (free phosphate). For NMR tests, approximately $300 \mu \mathrm{L}$ reaction solution was added into $\sim 1 \mathrm{~mL}$ Deuterium Oxide $\left(\mathrm{D}_{2} \mathrm{O}\right)$ (CAS\# 7789-20-0, Acros Organics, Lot B0758205, 99.8 atom\%) with 40 mg Tetraphenylphosphonium chloride $\left(\mathrm{C}_{6} \mathrm{H}_{5}\right)_{4} \mathrm{PCl}$ ) (CAS\# 2001-45-8, Sigma-Aldrich, 98wt\%, Mw=374.84 $\mathrm{g} / \mathrm{mol}$ ) as internal $\mathrm{P}$ standard. The NMR spectra were analyzed by "MestReNova Chemists" software to determine the concentration of off-line samples, which were integrated with online IR data to establish multivariant model.

\section{Quantitative NMR Data Analysis}

The quantitative P-NMR data were analyzed to determine the concentration of propionyl phosphate monoammonium (PrP mono) and free phosphate, as shown in Table S1.

Table S1. Calculation of the concentration of PrP mono and free phosphate based on quantitative P-NMR data

\begin{tabular}{|c|c|c|c|c|c|c|c|c|c|c|}
\hline $\begin{array}{l}\text { Offline } \\
\text { Sample } \\
\text { Name }\end{array}$ & $\begin{array}{c}\text { standard } \\
\mathrm{Ph}_{4} \mathrm{PCl} \\
\mathrm{Mw}, \\
\mathrm{g} / \mathrm{mol}\end{array}$ & $\begin{array}{c}\text { Free } \\
\text { phospha } \\
\text { te Mw, } \\
\mathrm{g} / \mathrm{mol}\end{array}$ & $\begin{array}{c}\text { PrP } \\
\text { mono } \\
\text { Mw, } \\
\mathrm{g} / \mathrm{mol}\end{array}$ & $\begin{array}{c}\text { standard } \\
\mathrm{Ph}_{4} \mathrm{PCl} \\
\text { integrate } \\
\text { d peak } \\
\text { area at } \\
22.5 \mathrm{ppm}\end{array}$ & $\begin{array}{c}\text { Free } \\
\text { phosphat } \\
\mathrm{e} \\
\text { integrate } \\
\mathrm{d} \text { peak } \\
\text { area at } \\
0.7-1.4 \\
\text { ppm }\end{array}$ & $\begin{array}{c}\text { PrP } \\
\text { mono } \\
\text { integrat } \\
\text { ed peak } \\
\text { area at } \\
\sim-2.2 \\
\text { ppm }\end{array}$ & $\begin{array}{c}\text { Charged } \\
\mathrm{Ph}_{4} \mathrm{PCl} \\
\text { std for } \\
\mathrm{NMR} \\
, \mathrm{g}\end{array}$ & $\begin{array}{l}\text { Charged } \\
\text { reaction } \\
\text { solution } \\
\text { for NMR, } \\
\mathrm{g}\end{array}$ & $\begin{array}{l}\text { Conc. } \\
\text { of PrP } \\
\text { mono } \\
\text { in } \\
\text { reaction } \\
\text { solution } \\
\text {, mol/L }\end{array}$ & $\begin{array}{l}\text { Conc. of } \\
\text { Free } \\
\text { phosphat } \\
\text { e in } \\
\text { reaction } \\
\text { solution, } \\
\text { mol/L }\end{array}$ \\
\hline $\begin{array}{c}5016073- \\
0037-A 1\end{array}$ & \multirow{5}{*}{374.84} & \multirow{5}{*}{96.99} & \multirow{5}{*}{171.09} & 1 & 0.08 & 0.50 & 0.1050 & 0.3295 & 0.45 & 0.07 \\
\hline $\begin{array}{c}5016073- \\
0037-A 2\end{array}$ & & & & 1 & 0.4 & 0.72 & 0.0537 & 0.3131 & 0.35 & 0.19 \\
\hline $\begin{array}{c}5016073- \\
0037-A 3\end{array}$ & & & & 1 & 0.76 & 0.52 & 0.0468 & 0.311 & 0.22 & 0.32 \\
\hline $\begin{array}{c}5016073- \\
0037-\mathrm{A} 4\end{array}$ & & & & 1 & 1.04 & 0.42 & 0.0417 & 0.3164 & 0.15 & 0.38 \\
\hline $\begin{array}{c}5016073- \\
0037-\mathrm{A} 5\end{array}$ & & & & 1 & 0.84 & 0.30 & 0.0526 & 0.3125 & 0.14 & 0.40 \\
\hline
\end{tabular}




\begin{tabular}{|c|c|c|c|c|c|c|c|}
\hline $\begin{array}{l}5016073- \\
\text { 0037-A6 }\end{array}$ & 1 & 2.12 & 0.51 & 0.0428 & 0.5699 & 0.11 & 0.45 \\
\hline $\begin{array}{l}\text { 5016073- } \\
\text { 0037-A7 }\end{array}$ & 1 & 1.4 & 0.27 & 0.0380 & 0.3282 & 0.09 & 0.45 \\
\hline
\end{tabular}

Conc of PrP mono in reaction solution is calculated by:

$$
\text { Conc. of PrP mono }=\frac{\mathrm{m}(\mathrm{Ph} 4 \mathrm{PCl}) \times \text { purity }(\mathrm{Ph} 4 \mathrm{PCl})}{\mathrm{Mw}(\mathrm{Ph} 4 \mathrm{PCl})} \times \frac{\text { Peak Area }(\mathrm{PrP} \text { mono })}{\text { Peak Area }(\mathrm{Ph} 4 \mathrm{PCl})} \times \frac{\text { density (reaction solution })}{\mathrm{m} \text { (reaction solution })}
$$

Conc of free phosphate in reaction solution is calculated by:

Conc. of free phosphate

$$
=\frac{\mathrm{m}(\mathrm{Ph} 4 \mathrm{PCl}) \times \text { purity }(\mathrm{Ph} 4 \mathrm{PCl})}{\mathrm{Mw}(\mathrm{Ph} 4 \mathrm{PCl})} \times \frac{\text { Peak Area (free phosphate })}{\text { Peak Area }(\mathrm{Ph} 4 \mathrm{PCl})} \times \frac{\text { density (reaction solution })}{\mathrm{m} \text { (reaction solution })}
$$

Note: purity of $\mathrm{Ph} 4 \mathrm{PCl}$ is $98 \%$; density of reaction solution is $1.07 \mathrm{~g} / \mathrm{mL}$

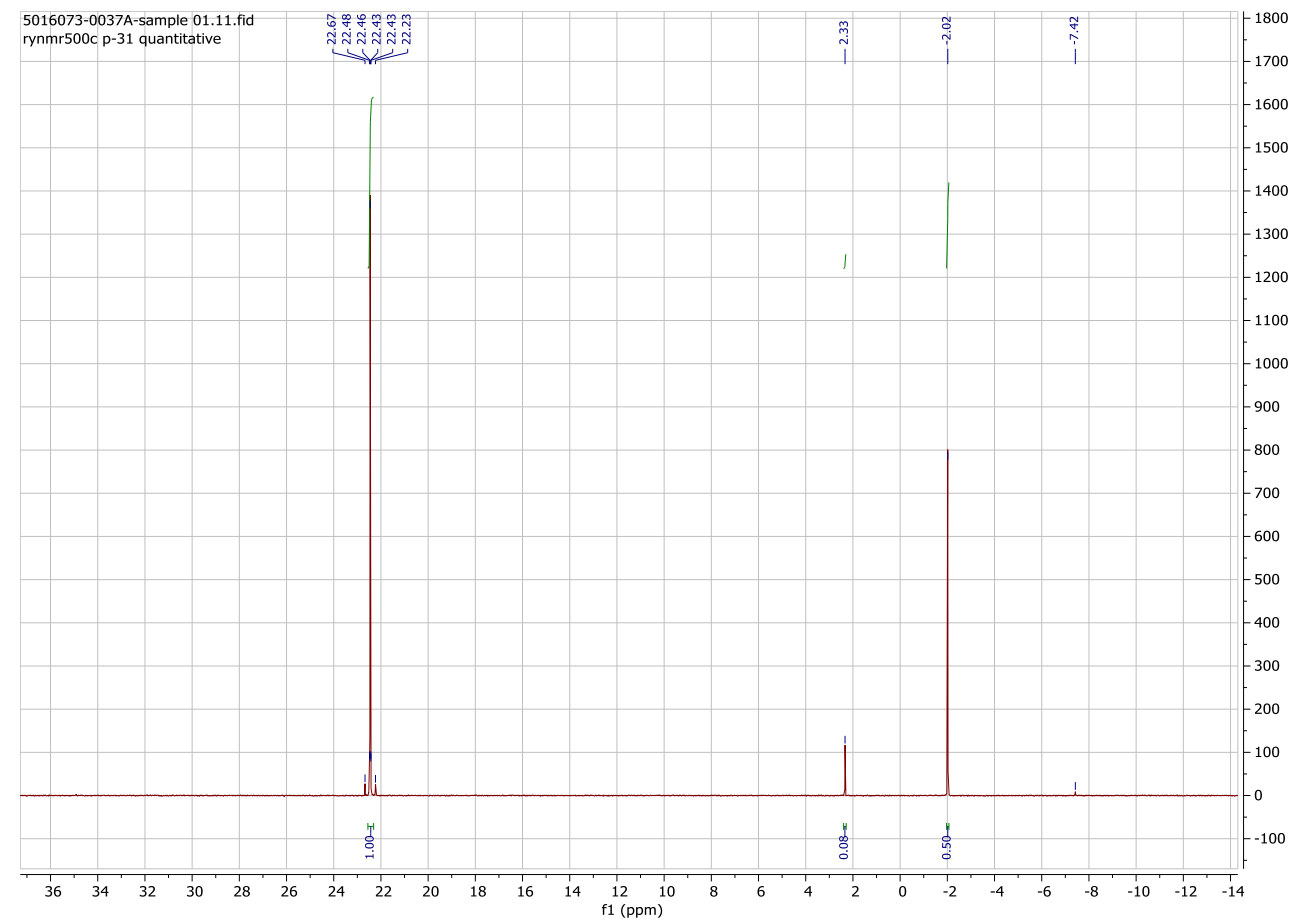

Figure S1. PNMR of Sample 5016073-0037-A1 


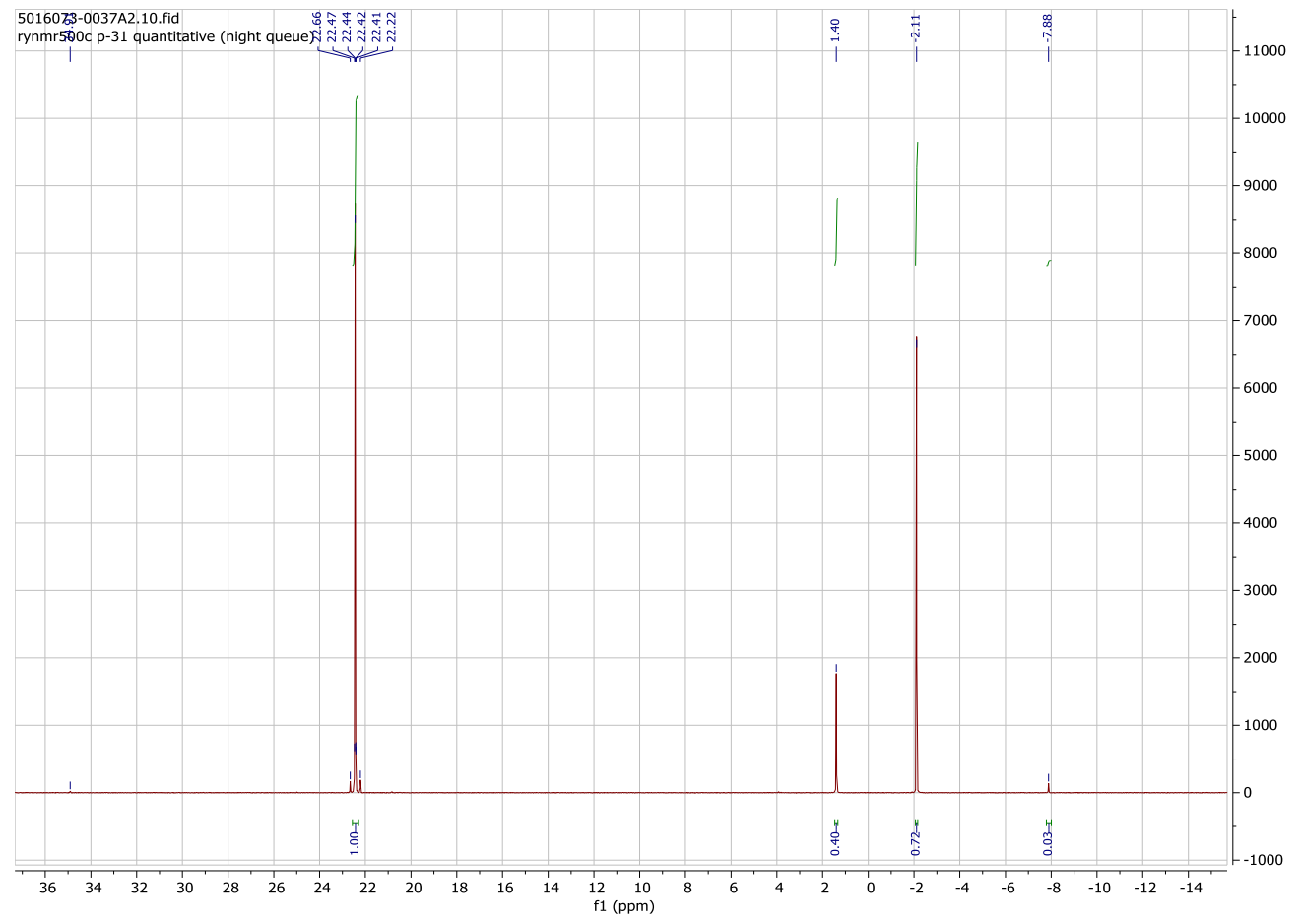

Figure S2. PNMR of Sample 5016073-0037-A2

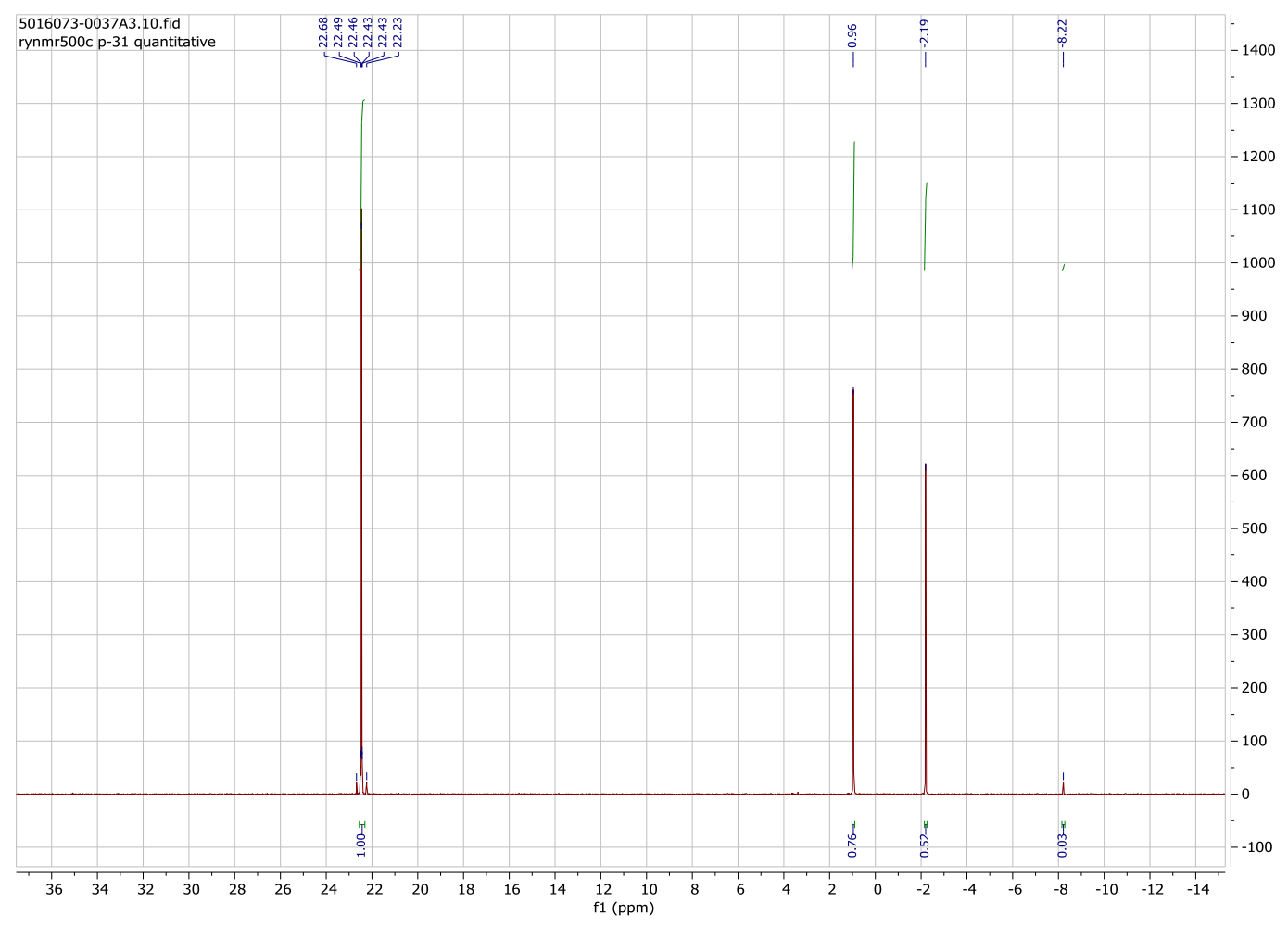

Figure S3. PNMR of Sample 5016073-0037-A3 


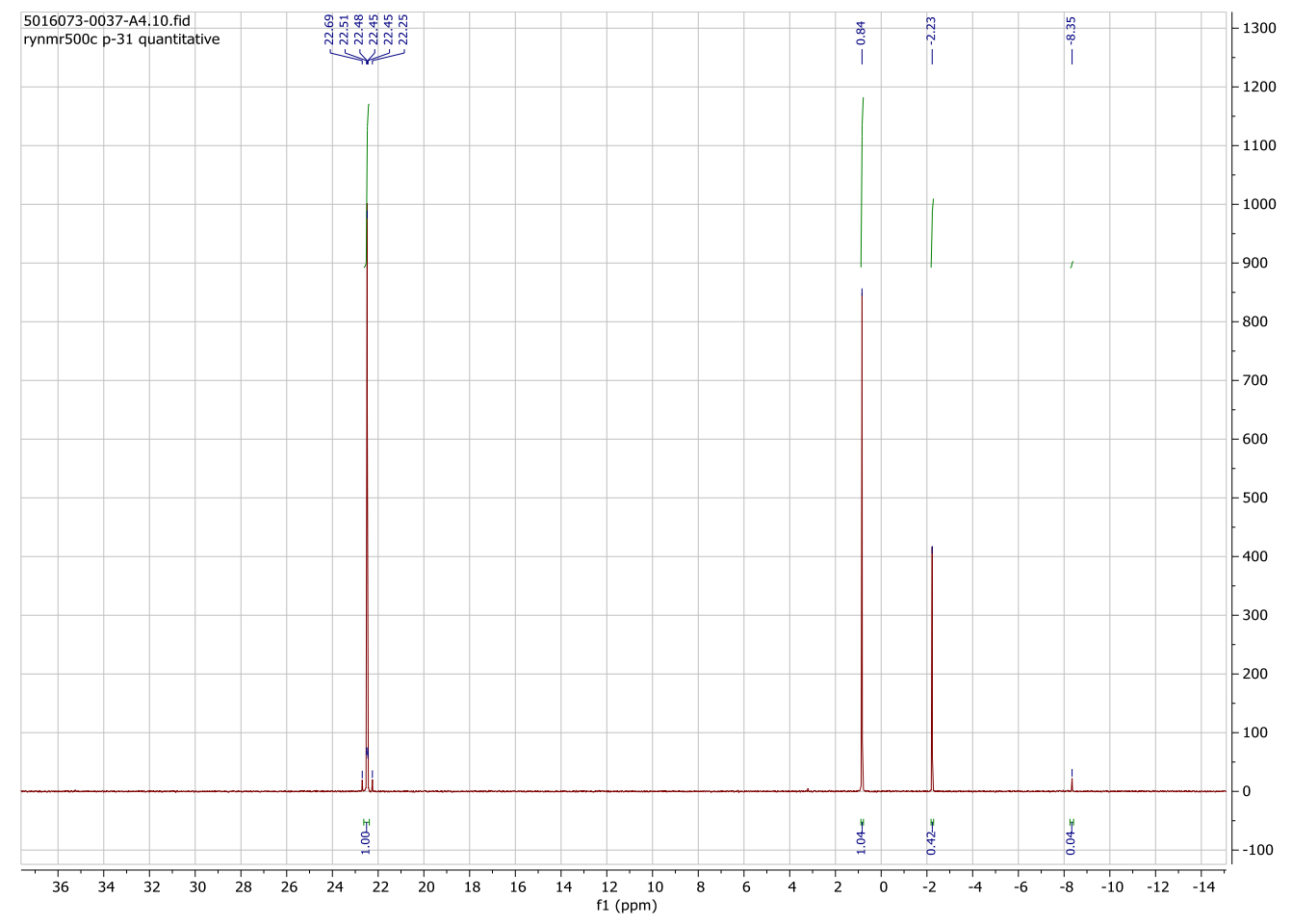

Figure S4. PNMR of Sample 5016073-0037-A4

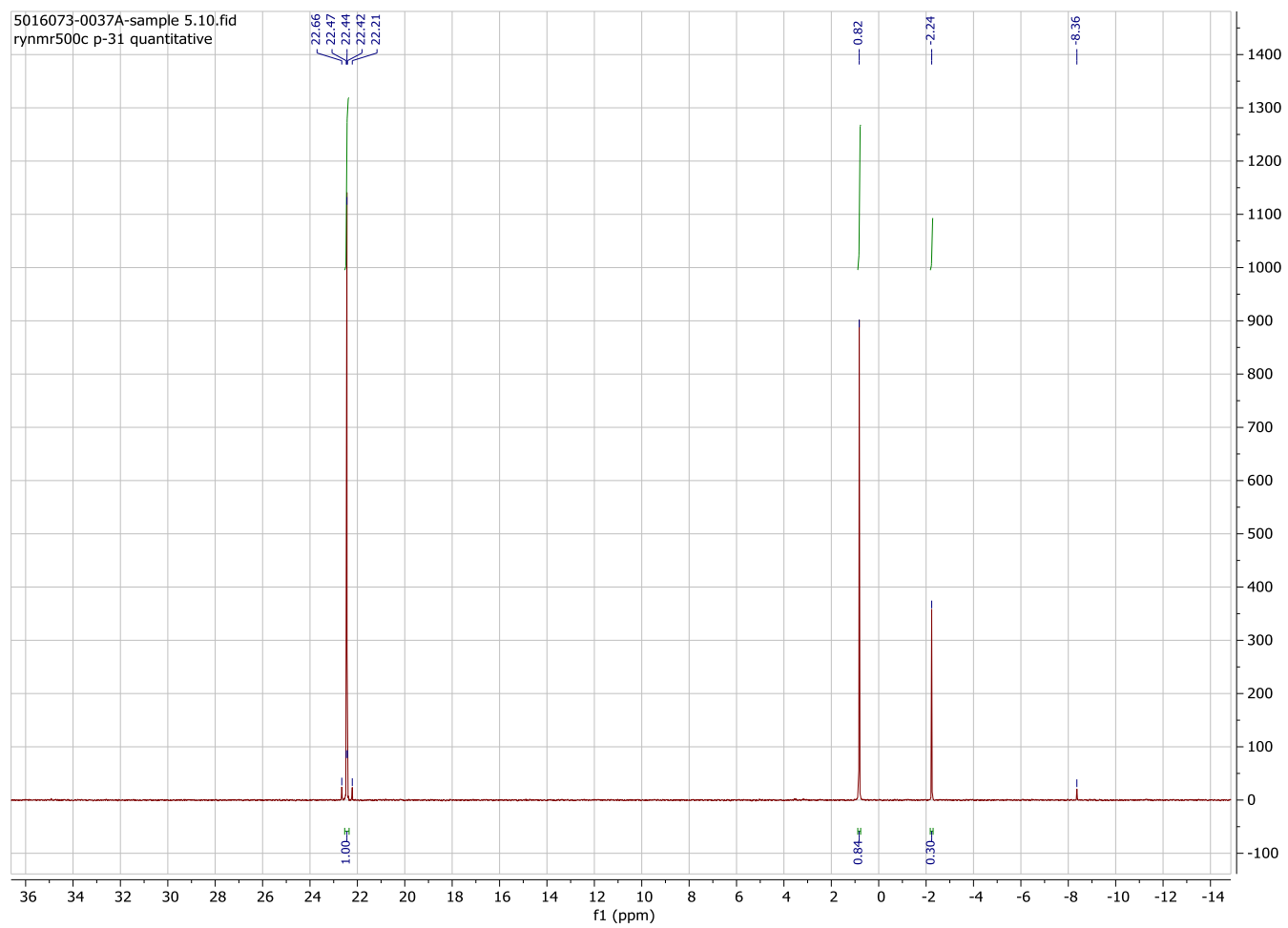

Figure S5. PNMR of Sample 5016073-0037-A5 


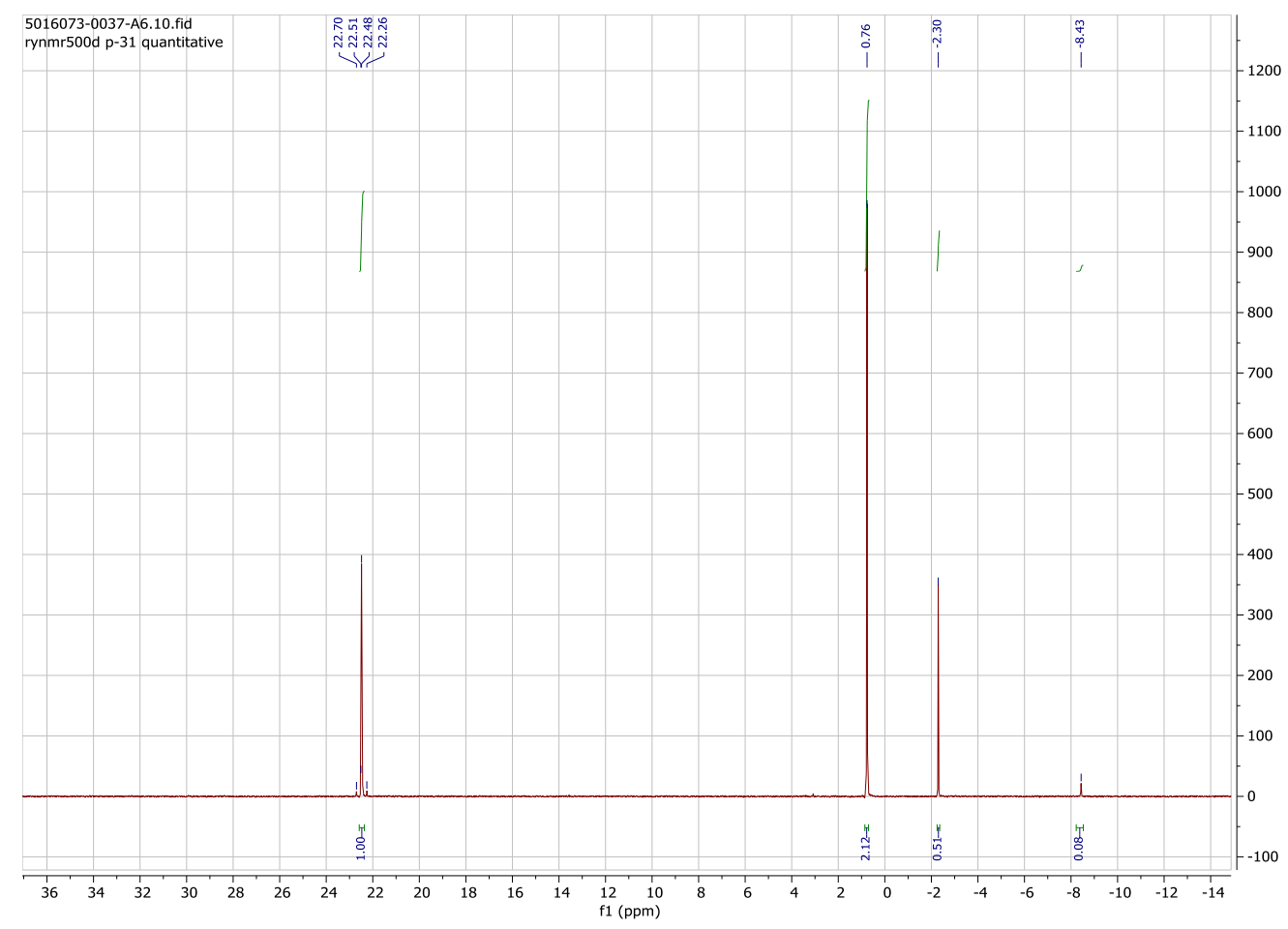

Figure S6. PNMR of Sample 5016073-0037-A6

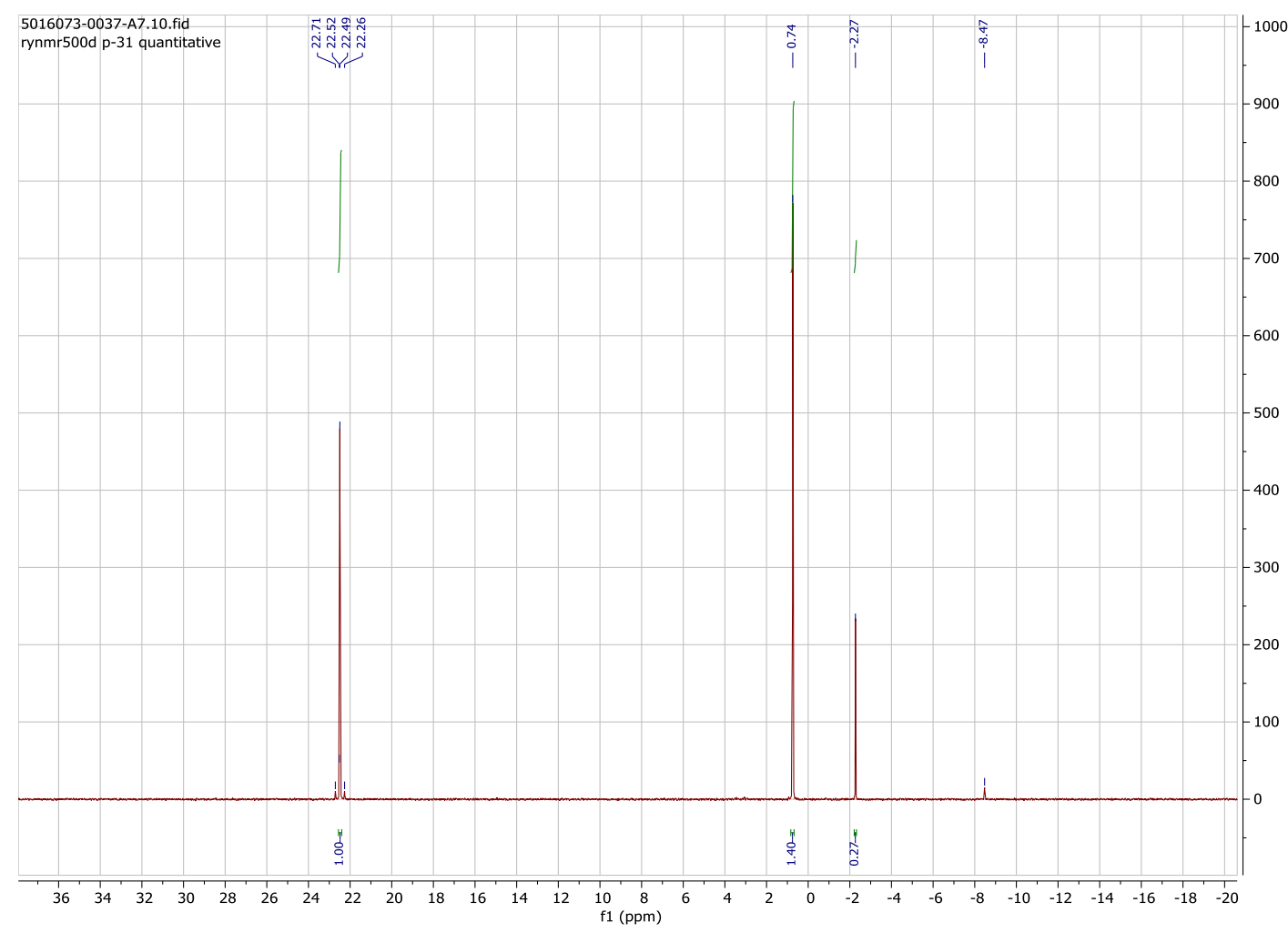

Figure S7. PNMR of Sample 5016073-0037-A7 


\section{Model validation}

In order to validate the kinetic model established using the experiment results presented in the main manuscript, another Repeated Temperature Scanning (RTS) experiment on the PrP mono hydrolysis reaction was conducted. As shown in Figure S8, in this dynamic run, the temperature ramping speed was controlled to be slower; the reactor internal temperature $(\operatorname{Tr})$ was programmed to increase from 5 to $35^{\circ} \mathrm{C}$ over 7 hours and then decrease from 35 to $5{ }^{\circ} \mathrm{C}$ over another 7 hours. Five ramping cycles were implemented continuously without any holding stages. 6 reaction samples were taken for offline P-NMR analysis, and the measured concentrations of PrP mono and free phosphate were used to calibrate in-situ FTIR data collected throughout the whole reaction process. The obtained concentration profile predicted by FTIR calibration model were then compared with the Dynochem kinetic model predicted concentration profile, as shown in Figure S9. In general, the concentration predictions by established kinetic model with Dynochem fit well with the FTIR measurement.

It should be noted the slight oscillation in FTIR trends (Fig S8) at the beginning of the reaction was a result of instrumental measurement fluctuation. The discrepancy between kinetic model prediction and FTIR measured concentration profile may be due to the FTIR calibration deviation. The performance of FTIR calibration model can be readily improved by adding some samples scanned by the new FTIR instrument.

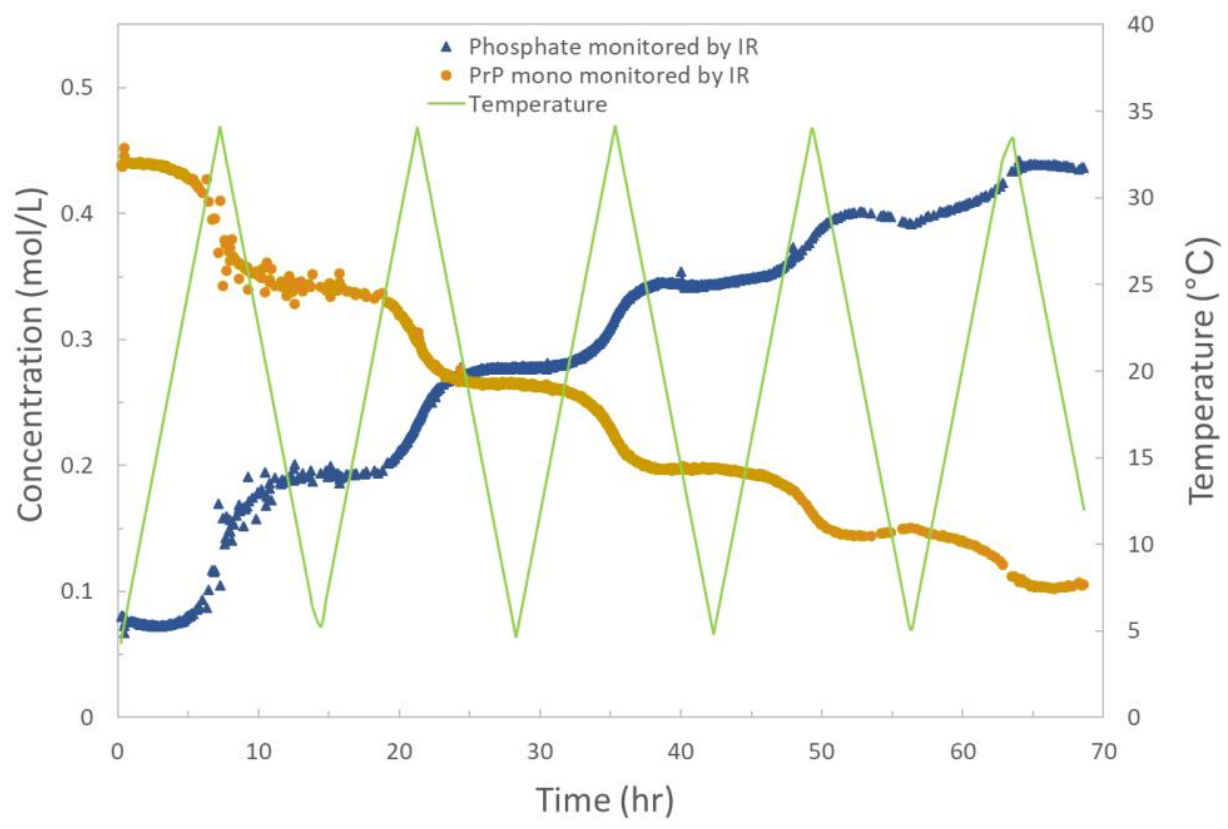

Figure S8. Real-time FTIR predictions of the concentrations by iPLS models and the time profile of the reaction temperature. 


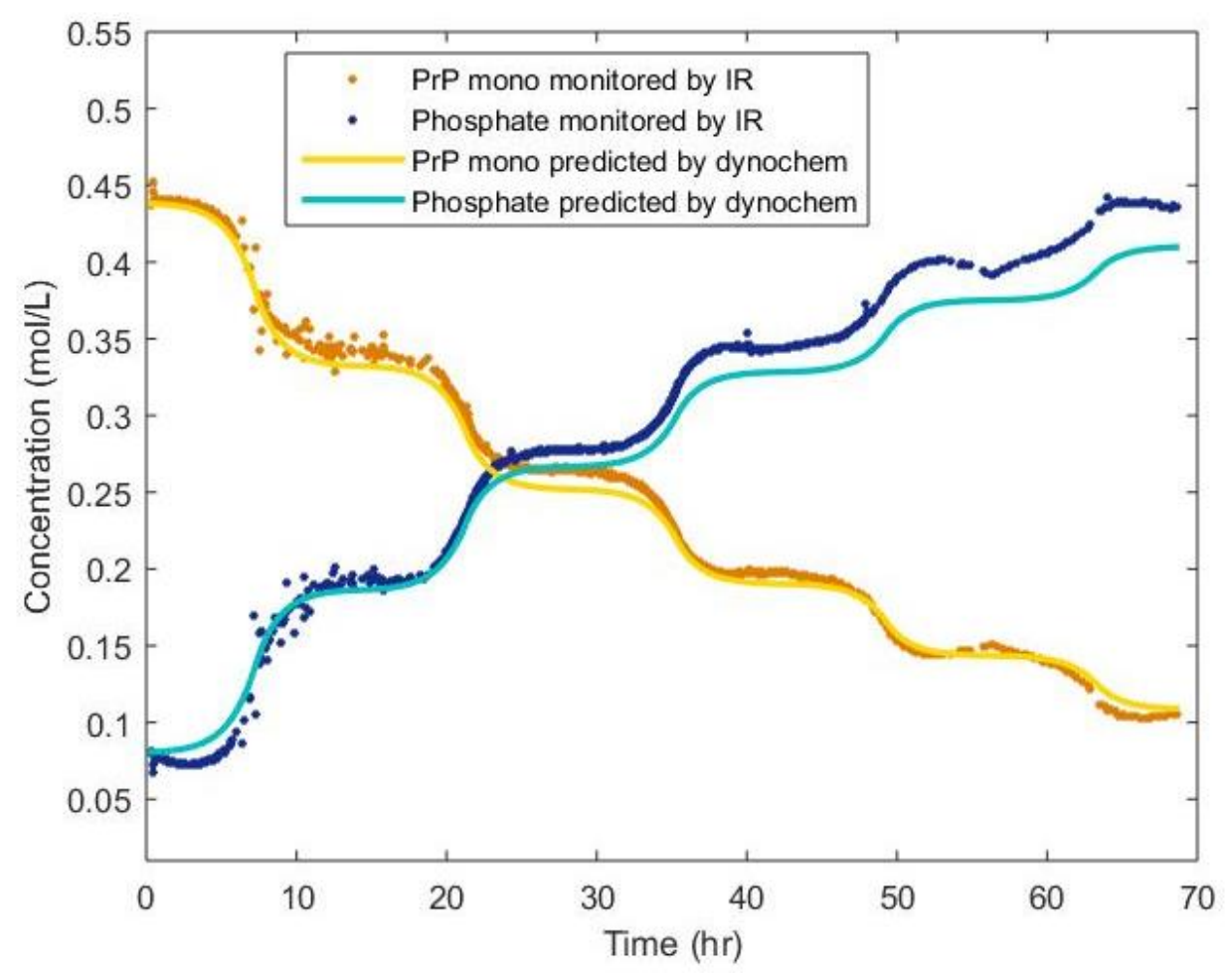

Figure S9. Validation of the dynochem kinetics model using the data collected under a slow ramping speed.

\section{4. $\underline{\mathrm{pH} \text { effect }}$}

We also have collected the $\mathrm{pH}$ value during course of reaction, as shown in Figure S10 listed below. The $\mathrm{pH}$ value during dynamic experiments is between 6 and 8.5, which is within $\mathrm{pH}$ independent region for such hydrolysis kinetics ${ }^{1}$. In Figure S10 (a) and (b), the correlation between $\mathrm{pH}$ and temperature indicates that the $\mathrm{pH}$ variation is only approximately $0.1-0.2$ due to $\mathrm{T}$ variation between $5-38{ }^{\circ} \mathrm{C}$. For example, Figure S10 (a) shows that between 48 and 53 hours, temperature decreases from 38 to $5{ }^{\circ} \mathrm{C}$, with negligible reaction ongoing (shown in the concentration profile in Fig.5), $\mathrm{pH}$ increases for 0.15 unit. The main reason of $\mathrm{pH}$ dropping over the whole course of experiments is mainly due to the formation of side product propionic acid. Therefore, we believe the results and established model presented in this manuscript are valid, due to the nature of $\mathrm{pH}$ independent kinetics of such hydrolysis reaction. 


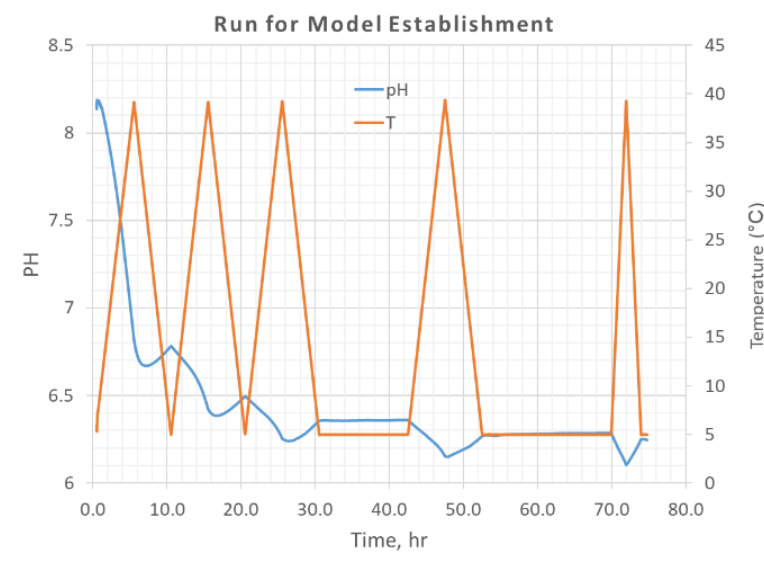

Figure $\mathbf{S 1 0}(\mathrm{a})$

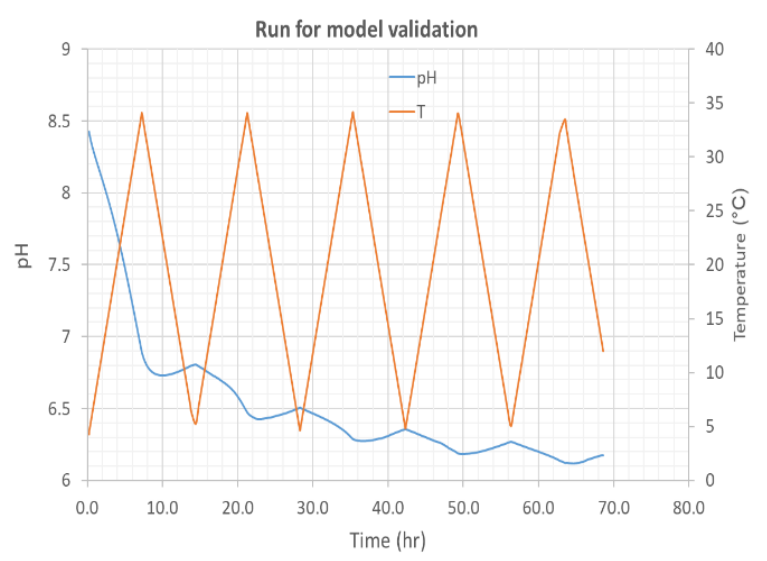

Figure $\mathbf{S 1 0}(b)$

\section{Reference}

1. Koshland, D. E., Effect of Catalysts on the Hydrolysis of Acetyl Phosphate. Nucleophilic Displacement Mechanisms in Enzymatic Reactions1. Journal of the American Chemical Society 1952, 74 , 2286-2292. 